\title{
Psychiatric and biochemical aspects of a case of homocystinuria
}

\author{
A. C. KAESER, ${ }^{1}$ R. RODNIGHT, AND B. A. ELlis \\ From the Institute of Psychiatry (British Postgraduate Medical Federation, University of London), \\ De Crespigny Park, London
}

Homocystinuria is an inborn error of metabolism, probably due to a recessive gene, which results in an absence of activity in the enzyme cystathionine synthetase, which converts homocystine to cystathionine in the liver and brain. Homocystine is normally absent from the body fluids, but occurs in the plasma and urine of affected subjects; it is derived from the amino acid methionine, present in the diet, so that there is also a tendency for plasma methionine levels to be high. The cause of the pathological lesions in homocystinuria is not known.

It was noted by Carson, Cusworth, Dent, Field, Neill, and Westall (1963) that a large number of relatives in one affected family was schizophrenic and subsequent case reports have recorded mentally ill relatives. There is one report in the literature of schizophrenia and homocystinuria occurring in the same patient (Spiro, Schimke, and Welch, 1965), the mother and five marernal relatives were also said to suffer from schizophrenia. Large doses of methionine prescribed with amine oxidase inhibitors produced behavioural changes in schizophrenics (Pollin, Cardon, and Kety, 1961 ; Park, Baldessarini, and Kety, 1965), and it has been suggested that there is an aetiological link between schizophrenia and disorders of transmethylation-for example, in the review by Smythies (1967).

Spaeth and Barber (1965) found that oral pyridoxine given to a homocystinuric led to a decreased excretion of homocystine in the urine. This has been confirmed by others, but only a proportion of patients respond (Hooft, Carton, and Samyn, 1967; Turner, 1967; Perry, Hansen, Love, Crawford, and Tischler, 1968). The case reported here was investigated biochemically and psychiatrically to throw light on these two problems.

\section{CASE HISTORY}

P.K., a male, age 26, was born in 1942 and was well until he presented, in August 1958, with a four-week history of gradually increasing illness beginning with a sore

${ }^{1}$ Present address: Runwell Hospital, nr. Wickford, Essex. throat and a minor pyrexia. He complained of a lump in his groin that he thought was produced by masturbation which examination revealed to be an easily reducible left indirect inguinal hernia. His anxiety became so marked that he was referred to a psychiatrist, who found that the patient was deluded with numerous hypochondriacal ideas, and advised prompt admission to hospital. The mother refused and sought a second opinion and he was referred to the Maudsley Hospital where he was observed as an out-patient for about four weeks. His state varied greatly from day to day, although there was a steady deterioration in his condition which led to his admission on 1 October 1958.

The patient complained that strange things had hap pened to his body: his legs felt as though they ha\& shrunk, the 'nerves had gone' at the back of the head 'as though something had dropped out', the gums and teet felt as though they were not in the right position, and his throat felt 'choked'. Periodically he felt frightened an\& 'fed up' but not particularly miserable; limbs and fingers felt stiff. A few days before admission he became drowsyo languid, and vomited. His parents noticed that he sweated profusely and that his urine was 'like strong tea'.

On examination he was drowsy and sweating profusely with a temperature of $37 \cdot 2 \mathrm{C}$, pulse $104 / \mathrm{min}$, and blood pressure of $240 / 170$, later $220 / 120 \mathrm{~mm} \mathrm{Hg}$. The heart was not enlarged; there was no papilloedema, and no vascular abnormality. No abnormality of the central nervous system could be found. All tendon reflexes were brisk; plantar responses were not elicited. His urine contained albumin, mucus, and granular casts, but no erythrocytes. Bilirubin, urobilinogen, and acetone were present in excess. A detailed psychiatric examination could not be performed, but he was correctly orientated and not obviously deluded. He was transferred next day to King's College Hospital for investigation and treatment.

PHYSICAL COURSE The jaundice subsided over two days, the albuminuria and slight uraemia by one month, and the tachycardia and pyrexia by six weeks. The hypertension persisted but fell gradually to levels around $130 / 90 \mathrm{~mm} \mathrm{Hg}$ over three months. Serial liver function tests showed a maximum serum bilirubin of $4 \mathrm{mg} \%$ and only transaminase abnormalites. On 6 October 1958 three grand mal fits were observed. Electroencephalograms on 8 October showed abnormal generalized slow activity 2 to $5 \mathrm{c} / \mathrm{s}$, most marked posteriorly. Subsequent records six and 13 weeks later showed resolution of the 
abnormality. A normochronic anaemia (Hb $10.0 \mathrm{~g}$ ) developed by seven weeks and then resolved. The ESR remained high throughout-for example, $50 \mathrm{~mm} / \mathrm{hr}$ Westergren. Urinary porphyrins were absent. Soleus muscle biopsy and numerous blood, urine, and cerebrospinal fluid tests contributed nothing. There was no evidence of phenothiazine administration before the jaundice.

PSYCHIATRIC COURSE In the general medical ward he was almost mute, immobile, doubly incontinent, ignored his visitors, responding occasionally to instructions to 'P.K.' as if he were a third person and spoke of himself likewise. At times he had catatonic rigidity and could be raised bodily by the head. After four weeks he suddenly became talkative, noisy, and excited and was transferred back to the Maudsley Hospital. Speech gradually returned to normal with periodic episodes of mutism, immobility, posturing, and inexplicable violence. On occasions he was deluded and showed thought disturbance-for instance, he refused food because he thought it was poisoned; he believed that a nurse was a Russian in disguise; that a nurse's actions symbolized an attempt to make him deaf; and that his hands belonged to his parents. All symptoms and signs resolved over three months and three months later he was back at work. A satisfactory diagnosis could not be made. He was treated with erythromycin (as septicaemia was initially suspected), barbiturates, and nursing care.

SUBSEQUENT COURSE During the next 10 years he was admitted to King's College Hospital three times for investigation and treatment of his hypertension. His heart steadily enlarged and the blood pressure remained elevated. In 1966 a right renal artery stenosis was demonstrated. He has had three admissions for acute glaucoma due to anterior dislocation of the right and left optic lenses.

In November 1966 the patient re-attended the Maudsley Hospital for a psychiatric report, for he had been arrested on a charge of exposing himself. No evidence of overt mental illness was found, but it was discovered that he was suffering from homocystinuria.

In February 1968 treatment with pyridoxine phosphate was started with the biochemical consequences described below. The initial dose was $300 \mathrm{mg} /$ day orally and this was increased to $450 \mathrm{mg} 17$ days later. There have been no untoward reactions.

CURRENT STATE Symptomatically there are no complaints. He complies with his instructions to avoid over-exertion. He has had numerous jobs, but has retained the present one as a storeman for one year. $\mathrm{He}$ lives with his mother, has few friends or interests, and is registered as a disabled person.

PSYCHOLOGICAL TESTS On the Wechsler Adult Intelligence Scale, his score was 72 (full scale), 78 (verbal) and 68 (performance). On the Graham Kendall Memory of Designs Test, the difference score was 7.5. On the General Aptitude Test Battery, all scores were below the minimum except the manual dexterity score which was just above.
It was concluded (1966) that he was slow to learn, but able to retain much of what he had learned, and that manual dexterity was relatively unimpaired. There was no other abnormality of the mental state.

PHYSICAL FEATURES Weight was $76.2 \mathrm{~kg}$, height $170.5 \mathrm{~cm}$, ground to pelvis height $93 \mathrm{~cm}$, span $181.5 \mathrm{~cm}$, radiographs of the thoracic and lumbar spine showed gross flattening of the vertebrae with herniation of the intervertebral discs. A high arched palate, bilateral iridodonesis, and dislocation of the optic lenses were present. The irides were blue. The hair was medium brown in colour, slightly wavy, and without abnormality of diameter or friability. Severe hypertension (blood pressure 200/125 $\mathrm{mm} \mathrm{Hg}$ ) was present with cardiac enlargement. A short right kidney and a right renal artery stenosis have been radiologically demonstrated. The peripheral pulses were all present and equal, venous thromboses were absent, and albuminuria was occasionally present.

No physical abnormalities of the central nervous system, respiratory or gastrointestinal tracts have been found. The following features sometimes seen in homocystinurics, were absent: malar flush, livedo reticularis, genu valgum, pigeon toes, flat feet, gait abnormality, overcrowded teeth, arachnodactyly, and chest deformity. The only hernia has been successfully repaired.

FAMILY HISTORY In 1958 the family consisted of mother, father, patient and his elder brother $\mathbf{M}$.

Brother M.K. had long had difficulty with his vision and, though aged 21 in 1958, had never been able to work -it was said because of this. However, he was also described as intellectually rather dull.

Shortly after P.K. was taken ill in 1958, M.K. developed a sore throat, some chest pains, and dyspnoea over a few hours. He was admitted to the same ward as his brother. Apart from severe dyspnoea, agitation, and tachycardia, little abnormality was found. He improved, but suddenly again became breathless one night a week later and died.

The antemortem and post-mortem findings included the following: height $170 \mathrm{~cm}$, bilateral dislocation of the optic lenses, mild arachnodactyly, an enlarged heart with endocardial and myocardial fibrosis and auricular thrombi, a thin narrow aorta with some areas of cystic medial nectosis. The lungs were congested with antemortem thrombus within the pulmonary arteries. The cause of death was attributed to pulmonary embolus though the source of the embolus was uncertain. The liver was waxy in appearance and histologically showed severe fatty change. The brain was found to contain recent small infarcts in the white matter of the right frontal cortex and there were several recent thrombi in the small vessels and signs of arteriosclerosis. Additionally, there was a prominent developmental abnormality of the left temporal lobe which has been fully described elsewhere (Robinson, 1964 - Case 10 in the temporal lobe agenesis syndrome).

Father The father, J.K. was a London docker. He remained well until December 1960 (then aged 54), when he started to develop a shakiness and tremor of the hands. He felt ill and unable to work. A hypertension was discovered (blood pressure $230 / 130 \mathrm{~mm} \mathrm{Hg}$ ) which 
was controlled by drugs. He gradually became more depressed, ruminated about suicide, and suffered with obscene thoughts about his relatives. He was retarded, tearful, looked prematurely old, with a slight stoop and a hint of Parkinsonism. He improved with ECT as a day patient but one year later he had not returned to work and was referred back for further treatment. Two weeks later he hanged himself. At necropsy, apart from the forensic findings, there was severe atheroma of the coronary arteries and cerebral vessels, with numerous areas of softening in the corpora striata.

In life there was no suggestion of mental illness before 1960 and no evidence of mental defect, severe ocular disturbance, or personality disorder.

Mother The mother is a healthy woman of 61 (1968) who is still at work. Her blood and urine have been examined and homocystine is absent.

It is almost certain that M.K. suffered from homocystinuria, as he had bilateral dislocated lenses, probable intellectual dullness, a fatty liver, and died at an early age, suddenly, of vascular thrombosis and embolism. However, his urine was not examined for homocystine.

Though detailed family histories were collected in 1958, and 1961-62, another check in 1967 failed to suggest evidence of homocystinuria elsewhere in the family. No one else appears to suffer or have suffered from a chronic mental illness, mental retardation, severe hypertension, or ocular difficulty. The two eldest paternal siblings died of unknown cause in early infancy.

BIOCHEMICAL INVESTIGATIONS Methods Venous blood was collected in heparin and plasma separated within $1 \mathrm{hr}$. Proteins were precipitated with picric acid and excess picrate removed with an anion exchange resin. The resulting extract was freeze-dried and the residue dissolved in $1 \mathrm{ml}$. $0.01 \mathrm{~N} \mathrm{HCl}$ for each ml. of plasma taken. Amino acids were determined on a Technicon automatic analyser using the standard Technicon $21 \mathrm{hr}$ gradient and cysteic acid as internal standard. Homocystine was eluted between phenylalanine and ammonia. The mixed disulphide of $\mathbf{L}$ cysteine and L-homocysteine was eluted between leucine and tyrosine, but in some early chromatograms it was poorly separated from leucine and could not be quantified.

Urine was collected over acetic acid and frozen pending analysis. The presence of excess homocystine was examined qualitatively with nitroprusside. Quantitative determinations of urinary homocystine derivatives were made by a modification of the method of Bessman,
Koppanyi, and Wapnir (1967) in which the colour yield of homocysteic and cysteic acids was measured spectrophotometrically after staining and elution from the paper according to Atfield and Morris (1961). The value quoted will include any mixed disulphides of cysteine and homocysteine present, although these were not positively identified.

Results Plasma amino acids were determined on five occasions before starting treatment with pyridoxine; values for homocystine, methionine, and cystine are given in Table I. All other amino acids were in the normal range. In the sample taken on 22 July 1967, the much lower values for methionine and homocystine were not reflected in the values for the non-sulphur amino acids, the levels of which were normal. The mixed disulphide of cysteine and homocysteine has been previously described in plasma from cases of homocystinuria (Carson et al., 1963; Brenton, Cusworth, and Gaull, 1965; Spaeth and Barber, 1965). In the present work its identity was confirmed by analysis of a plasma sample to which an authentic sample of the mixed disulphide had been added: only one enlarged peak was observed in the expected position.

The daily urinary excretion of homocystine derivatives (as homocysteic acid), ranged from 300 to $400 \mathrm{mg} / 24 \mathrm{hr}$ on three occasions. Cystine excretion (as cysteic acid) was approximately $100 \mathrm{mg} / 24 \mathrm{hr}$.

After oral administration of pyridoxine $(300 \mathrm{mg} /$ day $)$ the plasma homocystine level fell to about $50 \mu$-mole/1 $\Omega$ within a week and then further declined to $20 \mu$-mole/1 over the next fortnight (Fig. 1). Ten weeks later, only a trace of homocystine could be detected in a plasma sample taken after overnight fasting. Methionine levels remained mostly above the normal range after treatment but plasma cystine increased within a week to values about one half of normal. The 24-hour excretion of homocystine derivatives in the urine dropped from 380 to $153 \mathrm{mg}$ over the first five days of treatment. Further $24 \mathrm{hr}$ specimens were not collected, but a single sample tested 10 weeks later gave a negative nitroprusside reaction.

The results of methionine load tests administered orally ( $50 \mathrm{mg} / \mathrm{kg}$ body wt.) before and after ( 68 days) treatment are given in Fig. 2. In a normal male subject of similar physique and age, plasma methionine levels after the same load declined to $74 \mu$-mole/l. within $8.5 \mathrm{hr}$ of dosing; there was a $10 \%$ rise in plasma cystine over this period, but no appearance of homocystine in the plasma. There was little evidence from the load tests on the patient

\section{TABLE I}

PLASMA SULPHUR-AMINO ACIDS IN PATIENT

\begin{tabular}{|c|c|c|c|c|c|c|}
\hline \multirow{2}{*}{$\begin{array}{c}\text { S-amino acid } \\
(\mu-\text {-mole } / l . \text { plasma })\end{array}$} & \multirow{2}{*}{$\begin{array}{l}\text { Normal } \\
\text { fasting } \\
\text { range }\end{array}$} & \multicolumn{5}{|c|}{ Patient } \\
\hline & & $\begin{array}{l}18 / 4 / 67^{1} \\
\text { p.m. }\end{array}$ & $\begin{array}{l}22 / 7 / 67 \\
\text { a.m. }\end{array}$ & $\begin{array}{l}\text { 30/10/67 } \\
\text { p.m. }\end{array}$ & $\begin{array}{l}17 / 2 / 68 \\
\text { a.m. }\end{array}$ & $\begin{array}{l}19 / 2 / 68 \\
\text { a.m. }\end{array}$ \\
\hline $\begin{array}{l}\text { Methionine } \\
\text { Homocystine } \\
\text { Cystine } \\
\text { Mixed disulphide of L-cysteine and L-homocysteine }\end{array}$ & $\begin{array}{c}10-30 \\
0 \\
50-76 \\
0\end{array}$ & $\begin{array}{r}44 \\
146 \\
5 \\
\end{array}$ & $\begin{array}{r}15 \\
37 \\
5 \\
-\end{array}$ & $\begin{array}{r}45 \\
180 \\
5 \\
37\end{array}$ & $\begin{array}{r}41 \\
152 \\
5 \\
53\end{array}$ & $\begin{array}{r}36 \\
179 \\
5 \\
54\end{array}$ \\
\hline
\end{tabular}

ia.m. samples were taken before breakfast; p.m. samples were taken in the evening before supper. 
that pyridoxine therapy had improved his ability to metabolize an excessive load of methionine. Thus, there was an almost equal rise in homocystine levels in response to a load before and after therapy and plasma methionine levels remained high at $8 \mathrm{hr}$, suggesting that the pathway was still operating at a very low efficiency.

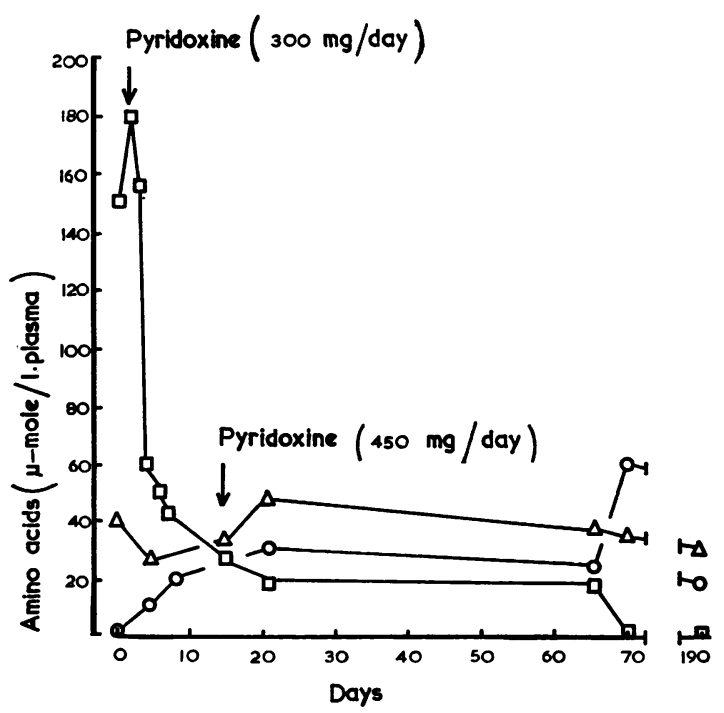

FIG. 1. Effect of oral pyridoxine (started on day 2) on levels of S-amino acids in plasma. $\square-\square=$ homocystine. $\triangle \longrightarrow \triangle=$ methionine. $\bigcirc \longrightarrow \bigcirc=$ cystine.
DISCUSSION

PSYCHIATRIC ASPECTS In the earliest case reports of homocystinuria encountered in populations of mental defectives, a striking number of their relatives were schizophrenics. Subsequent family histories have not been so convincing. The data are difficult to collect and the homocystinuric population is not at all clearly defined. For instance, the morbidity range varies from death at an early age to active life in the fifth decade, intelligence from idiots to university graduates, and abnormalities from gross to none (Schimke, McKusick, Huang, and Pollack, 1965; Spaeth and Barber, 1965). It may be relevant to recall that the early reports of phenylketonurics noted relatives with psychiatric disorder. It was suggested that the carrier gene predisposed to mental illness. It is only recently that two independent, carefully controlled studies have been able to throw serious doubt on this hypothesis (Perry, Tischler, and Chapple, 1966; Blumenthal, 1967).

At the moment, over 100 cases of homocystinuria have been described (Perry et al., 1968). Only one case clearly has schizophrenia as well (that of Spiro et al., 1965). Two others have had psychotic illness -Turner's 9-year-old girl and our own case. Price, Vickers, and Brooker (1968) after deliberation decided against a diagnosis of schizophrenia in their case. It is obvious that current methods of identifying cases could be producing a biased sample.

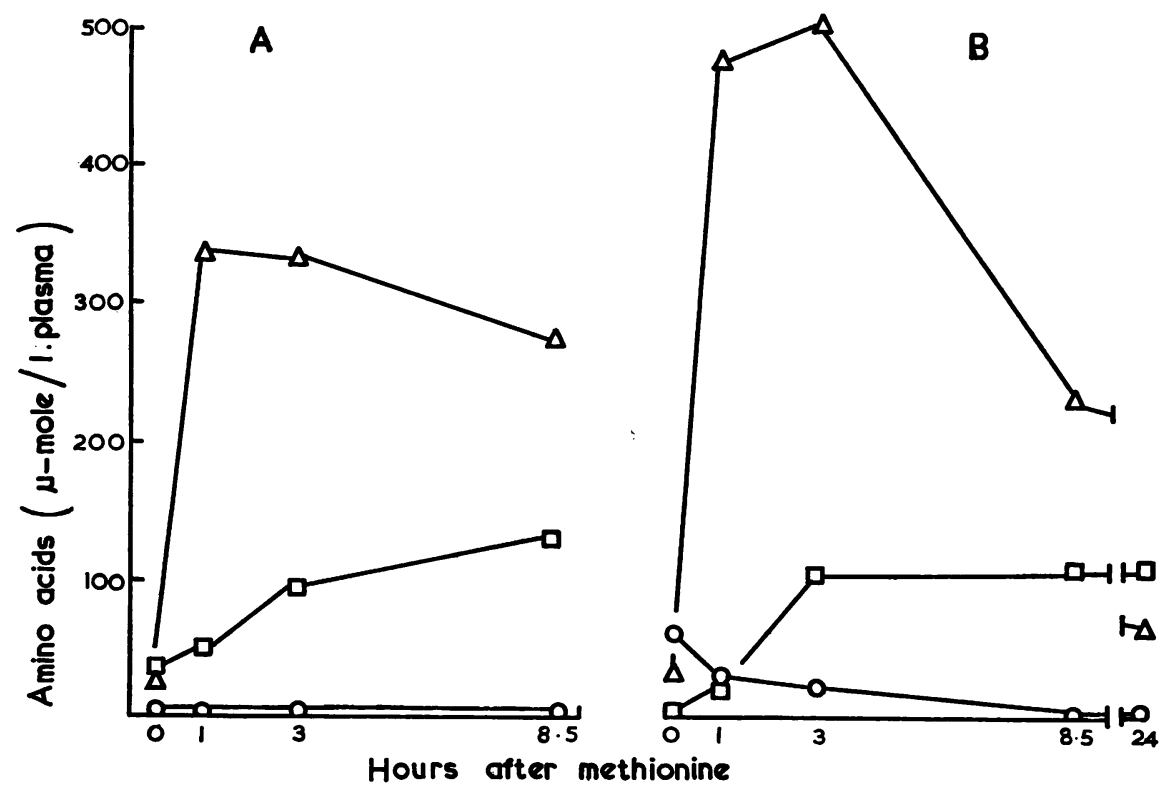

FIG. 2. Methionine load tests before (A) and 68 days after (B) starting pyridoxine treatment. $\square-\square=$ homocystine. $\triangle \longrightarrow \triangle$ = methionine. $\mathrm{O}-\mathrm{O}=$ cystine . 
The range of psychiatric disorder presented by P.K. over the span of 10 years is wide. One can make a good diagnostic case for the following at various points in the history: acute anxiety state, organic psychosis with catatonic features, reactive depression, personality disorder, sexual deviation, and mental defect. Indeed, if we include his brother, who was briefly suspected of hysterical hyperventilation, the range is nearly complete. However, the team of psychiatrists who looked after the patient in the psychotic phase rejected the diagnosis of schizophrenia.

If there is an association between homocystinuria and schizophrenia, it would appear logical to search for hidden cases in psychiatric hospital populations. Over 27,000 new cases have attended our joint hospital since 1960, since when all diagnoses have been card-coded and cross-referenced using the International Classification of Disease (ICD). Three categories of cards were sorted out and the case notes examined-namely, all codings under $388,753 \cdot 1$, and $758 \cdot 6$, which are concerned with malformations of the eyes and skeletal system; all joint codings of catatonic schizophrenia $(300 \cdot 2)$ and mental defect (325), and all joint codings of mental defect (325) and schizophrenia (300).

Of the 174 identifications thus made none of the case records suggested homocystinuria. We can only conclude that we have not found any evidence to suggest that a large number of homocystinurics have been referred to the hospital in the last seven years.

Two further points concerning our patient are of interest. First, in 1961, while depressed and being investigated at King's College Hospital for his hypertension, he was given the monoamine oxidase inhibitor phenelzine, $15 \mathrm{mg}$ t.d.s. for five weeks and it was reported to be helpful. Secondly, his methionine load tests did not produce any symptoms or behavioural change.

BIOCHEMICAL ASPECTS A reduction in plasma and urinary levels of homocystine after administration of pyridoxine has been observed in some cases of homocystinuria, but not in others (Barber and Spaeth, 1967; Chase, Goodman, and O'Brien, 1967; Hooft et al., 1967; Schimke and Weilbaecker, 1967; Turner, 1967; Perry et al., 1968; Carson, personal communication, 1968). The explanation for this inconsistent effect of pyridoxine is not known. The vitamin is a co-factor for cystathionine synthetase and it is possible that in responding cases the genetic error has resulted in the synthesis of an abnormal enzyme with a greatly reduced ability to bind pyridoxine, but one which can be partially reactivated in the presence of a great excess. Such a mechanism has been suggested for the analogous effect of pyridoxine on cystathionine excretion in cystathioninuria (Frimpter, Haymovitz, and Horwith, 1963).

It is noteworthy that our patient continued to respond abnormally to a methionine load after some weeks of pyridoxine therapy. This shows that, despite the absence of homocystine in his blood and urine, the pathway was still operating at only a low level of efficiency. It is possible that in affected subjects who do not respond to pyridoxine the degree of enzyme defect may be too severe to allow reactivation by exposure to excess co-factors. It may be significant that plasma methionine levels in our patient have always been relatively normal, whereas in the cases of Chase et al. (1967) and Perry et al. (1968) who failed to respond to pyridoxine plasma methionine levels were raised several times above normal. Environmental factors may also condition enzyme co-factor interaction and the different responses of homocystinurics to pyridoxine do not necessarily point to two distinct genetic conditions.

One of the striking effects of pyridoxine treatment in our subject was to raise the plasma cystine level from zero to about one half the normal level (Figg 1). In two separate experiments (of which one shown in Fig. 2B), this raised plasma cystine level fe to zero within hours of administering a methioning load. We are unable to explain this curious observas tion. In normal individuals methionine loading has little effect on plasma cystine levels, although it ing creases the urinary output of cystine metabolites Since methionine and cystine transport appear no을 mal in the condition (Brenton et al., 1965), this rèsponse is unlikely to have a renal origin. Possibly the excess methionine in the body calls forth other pyridoxine dependent reactions, such as transamination, which successfully compete for the loosely-bound pyridoxine in the cystathionine pathway.

\section{SUMMARY}

A homocystinuric adult with minor mental defect who has suffered from a psychosis and other psychiatric disorders is described. Treatment with pyridoxine resulted in a marked lowering of the 3 . plasma and urinary levels of homocystine but no change was demonstrated in his ability to metabolize a methionine load. The findings are discussed in 0 relation to their aetiological implications for psychosis and enzyme function.

We are grateful to the Board of Governors of the $\mathrm{N}$ Bethlem Royal and Maudsley Hospitals for a grant from $\mathrm{N}$ the Hospital Research Fund in support of this work. We would also like to thank Dr. Denis Leigh and Dr. $\omega$ R. Bruce Pearson for their help and encouragement, $\underset{<}{ }$ 
Dr. N. A. J. Carson for advice about pyridoxine treatment of homocystinuria, and especially Dr. J. J. Lopez Ibor who suggested the diagnosis.

\section{ADDENDUM}

Our attention has been drawn to an early reference (Cerecedo, L. R., Foy, J. R., and De Renzo, E. C. (1948), Protein intake and vitamin $B_{6}$ deficiency in the rat. II. The effect of supplementing a lowprotein, pyridoxine deficient diet with cystine and methionine. Arch. Biochem., 17, 397-402), reporting an exacerbation of the symptoms of pyridoxine deficiency in rats receiving a high methionine intake.

\section{REFERENCES}

Atfield, G. N., and Morris, C. J. O. R. (1961). Analytical separation by high-voltage paper electrophoresis. Amino acids in protein hydrolysates. Biochem. J., 81, 606-614.

Barber, G. W., and Spacth, G. L. (1967). Pyridoxine therapy in homocystinuria. Lancet, 1, 337.

Bessman, S. P., Koppanyi, Z. H., and Wapnir, R. A. (1967). A rapid method for homocystine assay in physiological fluids. Anal. Biochem., 18, 213-219.

Blumenthal, M. D. (1967). Mental illness in parents of phenylketonuric children. J. psychiat. Res., 5, 59-74.

Brenton, D. P., Cusworth, D. C., and Gaull, G. E. (1965). Homocystinuria: metabolic studies on 3 patients. J. Pediat., 67, 58-68.

Carson, N. A. J., Cusworth, D. C., Dent, C. E., Field, C. M. B., Neill, D. W., and Westall, R. G. (1963). Homocystinuria: a new inborn error of metabolism associated with mental deficiency. Arch. Dis. Childh., 38, 425-436.

Chase, H. P., Goodman, S. I., and O'Brien, D. (1967). Treatment of homocystinuria. Ibid., 42, 514-520.
Frimpton, Haymovitz, A., and Horwith, M. (1963). Cystathioninuria. New Engl. J. Med., 268, 333-339.

Hooft, C., Carton, D., and Samyn, W. (1967). Pyridoxine treatment in homocystinuria. Lancet, 1, 1384.

Park, L. C., Baldessarini, R. J., and Kety, S. S. (1965). Methionine effects on chronic schizophrenics. Patients treated with monoamine oxidase inhibitors. Arch. gen. Psychiat., 12, 346-351.

Perry, T. L., Tischler, B., and Chapple, J. A. (1966). The incidence of mental illness in the relatives of individuals suffering from phenylketonuria or mongolism. J. psychiat. Res., 4, 51-57.

—- Hansen, S., Love, D. L., Crawford, L. E., and Tischler, B. (1968). Treatment of homocystinuria with a low-methionine diet, supplemental cystine, and a methyl donor. Lancet, 2, 474-478.

Pollin, W., Cardon, P. V., Jr., and Kety, S. S. (1961). Effects of amino acid feedings in schizophrenic patients treated with iproniazid. Science, 133, 104-105.

Price, J., Vickers, C. F. H., and Brooker, B. K. (1968). A case of homocystinuria with noteworthy dermatological features. J. ment. Defic. Res., 12, 111-118.

Robinson, R. G. (1964). The temporal lobe agenesis syndrome. Brain, 87, 87-106.

Schimke, R. N., McKusick, V. A., Huang, T., and Pollack, A. D. (1965). Homocystinuria: studies of 20 families with 38 affected members. J. Amer. med. Ass., 193, 711-719.

_ and Genetic Variation. Edited by W. L. Nyhan. McGraw-Hill: New York.

Smythies, J. R. (1967). Recent advances in the biochemistry of schizophrenia, pp. 61-68 in Recent Developments in Schizophrenia. A Symposium. (Brit. J. Psychiat., Special Publication, No. 1). Psychological Association: London.

Spaeth, G. L., and Barber, G. W. (1965). Homocystinuria in a mentally retarded child and her normal cousin. Trans. Amer. Acad. Ophthal. Otolaryng., 69, 912-930.

Spiro, H. R., Schimke, R. N., and Welch, J. P. (1965). Schizophrenia in a patient with a defect in methionine metabolism. J. nerv. ment. Dis., 141, 285-290.

Turner, B. (1967). Pyridoxine treatment in homocystinura. Lancet, 2, 1151. 